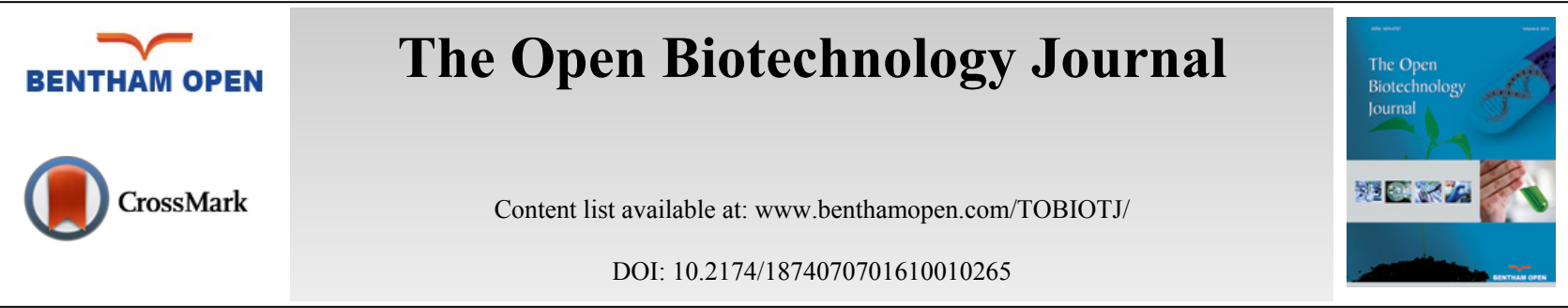

\title{
RETRACTION
}

\section{Retraction Notice: On the Recognition, Measurement and Disclosure of Forest Biological Assets}

Linfang $\mathrm{Hou}^{*}$

School of Economics and Management, Zhoukou Normal University, Zhoukou, 466001, Henan, China

\section{RETRACTION}

The Publisher and Editor have retracted this article [1] in accordance with good ethical practices. After thorough investigations we believe that the peer review process was compromised. The article was published online on 14-09-2015.

\section{REFERENCE}

[1] Hou L. On the recognition, measurement and disclosure of forest biological assets. Open Biotech J 2015; 9: 165-9. 